\title{
Promises and hurdles of undergraduate medical development in Greece
}

This article was published in the following Dove Press journal:

Advances in Medical Education and Practice

23 September 2011

Number of times this article has been viewed

\author{
Amalia A Ifanti' \\ Andreas A Argyriou ${ }^{2}$ \\ Haralabos P Kalofonos ${ }^{2}$ \\ 'Department of Educational Sciences \\ and Early Childhood Education, \\ University of Patras, ${ }^{2}$ Department \\ of Medicine, Division of Oncology, \\ University Hospital of Patras, Rio, \\ Patras, Greece
}

Aim: In this paper we sought to explore undergraduate medical students' views about their professional development during their studies that are considered to be related to medical professionalism.

Method: A descriptive cross-sectional study using interpretative analysis of anonymous 10-item questionnaires was conducted at the University of Patras Medical School (UPMS), Greece. The study sample consisted of 134 undergraduate students in their fifth and sixth year of study at UPMS.

Results: Undergraduate students emphasized the great significance of daily clinically-oriented practice in the wards in the group of behaviors consistent with medical professionalism. The integrated curriculum and informal discussions with members of the academic staff in the form of role models were also regarded as valuable approaches strongly enhancing professionalism. Students' personal statements contained attributes regarding premium professional skills, including constancy and perfectionism throughout a lifelong learning process, so as to be able to provide high quality medical care to patients.

Conclusion: According to our undergraduate medical students themselves, the last 2 years of their studies are important to understand the essence of professionalism and develop their professional medical attitudes. Clinically-oriented teaching activities together with the informal curriculum of enhanced role modeling promote medical professional behaviors and increase standards of health care provided to patients.

Keywords: undergraduate students, medicine, professionalism, medical education, Greece

\section{Introduction}

Aristotle, the Greek ancient philosopher, claimed that there were three basic activities of man: theoria (theory), poiesis (poetry), and praxis (action). ${ }^{1} \mathrm{He}$ defined praxis as a process by which a theory, a lesson, or skills are practised, embodied, and/or realized in the context of political, educational, and spiritual realms. Praxis, when referred to educational matters, is described as the action and reflection of people upon their world in order to transform it, and thus pursue social justice. ${ }^{2}$ It is currently maintained that praxis is important in medical lifelong learning as well as in service learning programs because it can play an important role in developing young physicians' conceptions of professional duties. ${ }^{3}$

The modern role of a physician encompasses functions, such as healer, professional, and scientist. Although these roles appear to be separate and distinct, young doctors are currently expected to cope with their duties competently. The existing guidelines for 
medical education require undergraduate students to develop proper attitudes towards professionalism. ${ }^{4}$

Professionalism, in turn, builds upon the objectives, attributes, and behaviors that characterize a profession, whereas a professional is defined as a person having a paid vocation, founded upon specialized educational training in the field in which they are practising professionally. Apart from being highly skilled in relation to their profession, a professional should also attain high standards of professional ethics and work activities, often putting the interest of the client ahead of the professional's interests. ${ }^{5}$

Furthermore, medical professionalism is considered as the behavior defining the relationship of a physician to patients and society, thus serving as the infrastructure for the trust that is absolutely necessary to the patientphysician relationship. ${ }^{6,7}$ The term is multidimensional and encompasses the values, behaviors, and attitudes inculcated through medical school education and postgraduate training together with the experiences gained during daily interaction with patients and fellow physicians. Doctors, therefore, are expected to comprehend the true meaning of professionalism and pay particular attention to sustain it.

Recent literature contains several reports that propose a new definition of professionalism, whereas some of them dispute the validity of the concept of medical professionalism in the current era and urge the need for structural changes in order for the work of medical professionals to adapt to changing health needs. ${ }^{8,9}$ Nowadays, changing medical professionalism to fit modern health needs appears to be essential for achieving the ultimate goal of medicine, which is to optimize the health of both individuals and society. The need to respond vigorously to that challenge led medical education authorities worldwide to shape their curriculum in order to create learning environments that will allow undergraduate students to gain both professional and humanistic attitudes, thus providing high quality health care to patients. ${ }^{10}$

Apart from the implementation of a formal syllabus addressing professionalism, the development of effective programs for role modeling and mentoring in medical schools towards the cultivation of medical professionalism in students seems to be paramount for maintaining a high medical professional status. ${ }^{11-13}$ Students' views and attitudes concerning medical professionalism seem to be an important issue and should not be disregarded by medical schools' authorities when reforming their curriculum.

Over recent years, the inculcation and assessment of medical students' professionalism have attracted attention and as such the current literature contains several relevant studies. ${ }^{14-17}$ However, there has been little comparison of attitudes of undergraduate students concerning medical professionalism across cultures and educational systems. The degree to which medical students are aware and perceive professionalism may significantly differ in various countries depending on the curriculum, the educational programs promoting professionalism, the continuing changes that occur in national health systems, and on values and habits. ${ }^{7}$ The lack of a valid instrument to assess professionalism may also significantly contribute to the diversity of available data. ${ }^{18}$

In this setting the authors report on Greek medical undergraduate students' perceptions about their professional development during their studies. To the best of the authors' knowledge, this case study attempts for the first time to delineate the attitudes of undergraduate Greek students relating to medical professionalism. This study seeks firstly to explore the theoretical concept of professionalism among undergraduate students attending the University of Patras Medical School (UPMS), Greece. In particular, the context in which the disease, the health service, and the medical profession are encountered is examined. The relationship between the UPMS curriculum, some characteristics of professionalism, and the factors that are being identified by students as contributing to their professional development during their undergraduate studies are also examined.

\section{UPMS}

UPMS was founded in July 1977 by Law 641/1977 ${ }^{19}$ and was renamed as the School of Health Sciences in 1983 (Presidential Decree 127/1983), ${ }^{20}$ consisting of the Department of Medicine and the Department of Pharmacy. Each academic unit has its own hierarchical and decision-making structure. There is an administrative hierarchy in the six ranks of the institutional structure concerning leadership and decision-making, with the Senate at the top following by the Rector, Dean of the School, General Assembly of each Department, Chairman of the Department, Director of the Division, and representatives of the teaching staff. The Senate, in its session held on December 2008, decided to rename the Department of Medicine as Medical School (Reference number: 436/18.12.08).

\section{Undergraduate medical syllabus of UPMS for the 2009-2010 academic year}

Undergraduate medical studies are offered by the UPMS (medical degree) and are extended to 6 years. Students are admitted to UPMS, according to their performance at national level examinations, after they are asked to state the faculty 
of their choice among the seven available medical schools in Greece. ${ }^{21}$ Undergraduate studies are divided into two branches: preclinical and clinical. Preclinical (basic) studies generally extend into the first 4 years and include classroom teaching and laboratory practice in relation to the core subjects of the curriculum, eg, anatomy, biochemistry, physiology, microbiology, pathology, and pathophysiology. The clinical part usually coincides with the final 2 years of study (ie, fifth and sixth year) and takes place almost exclusively in the wards of the teaching hospital where students observe and participate in the care of patients under the supervision of residents; they also follow the physicians and members of medical academic staff in everyday clinical work.

At UPMS preclinical activities are housed in a new $20,000 \mathrm{~m}^{2}$ building while clinical units occupy a 750 bed university hospital next to the preclinical building. A new building hosts the research laboratories of the clinical departments. The medical complex also includes a building where teaching amphitheaters and the medical library are located.

The main educational objectives of the undergraduate medical curriculum for the 2009-2010 academic year were three-fold. The first objective is to educate future physicians in the fundamental biological and medical sciences and to help them develop the medical skills necessary for the efficient and effective treatment of patients. An equally important objective is to make students acquainted with the values and ethical principles which are necessary for professional medical practice. Moreover, the UPMS has made excellence in the fields of basic and applied research, on the basis of international assessment, a priority. Therefore, another important aspect of the educational syllabus is to generate and further develop research skills of undergraduate students.

Professionalism is not addressed during targeted faculty programs with an integrated sequence of courses in the UPMS syllabus. However, it is promoted in the context of a white-coat ceremony in which matriculating students take a professional oath of ethical conduct, thus affirming their professional commitment. ${ }^{22}$

\section{Study sample and methods}

Male and female undergraduate Greek students in either their fifth or sixth year of study (the clinical part of the syllabus) at UPMS were randomly selected to take part in this crosssectional self-completed survey which was carried out in the second semester of the 2009-2010 academic year.

On a random teaching day, fifth- and sixth-year students, either in the medical library or attending courses in the amphitheatre $(n=150)$, were approached and the first consecutive students who consented to participate were given the questionnaire by a researcher who explained the purpose of the study. According to official records, the total number of registered fifth and sixth year students was $240 ; 150$ of them were found on the day of the survey and 134 responses were received $(89.3 \%$ response rate). They were then asked to self-complete the questionnaire without supervision or any other assistance. Participants were not identified by name and their data were stored in an anonymous form for interpretative analysis.

The questionnaire consisted of ten items. Nine items were in a closed-ended format, thereby requiring participants to choose from a limited number of responses predetermined in the questionnaire. The first question (item 1) was a categorical (yes/no answer), three questions (items 4, 7, and 10) were ordinal, three questions (items 3, 5, and 9) asked to rate a specific item on a 5-point Likert-type scale, and two were multiple choice questions (items 2 and 6). The remaining item (item 8) was in an open-ended format. Demographic data, including gender and the year of study, were also recorded.

The first two items of the questionnaire asked students to state whether UPMS was their faculty of choice and to give an explanation on that. The third item of the questionnaire asked them to report whether, and to what degree, the clinical experience gained over their fifth and sixth year of study in the teaching hospital contributes to the constellation of behaviors consistent with medical professionalism. The fourth item was concerned with the investigation of students' ideas about the best teaching approach to their studies that could promote their professionalism. The fifth item referred to students' views about the role of compulsory participation in clinically-oriented teaching programs and its contribution to their professional development. In the sixth item, students were asked to report whether a possible relationship between the clinical and the preclinical branches of the syllabus might develop attitudes related to medical professionalism.

In the seventh question, students were asked to specifically evaluate the significance of an integrated curriculum, which has been implemented in this medical school since the 2006-2007 academic year. An integrated medical curriculum refers to a noncompartmentalized approach to basic science learning and helps students make connections across curricula. It is based on the problem-based learning theory that alternates lectures on different topics of medicine over the course of study. According to this educational approach, the medical curriculum is divided into a number of interdisciplinary "blocks." Each "block” focuses on the study 
of organ systems of the human body and it is being developed with the contribution of specialists from clinical and basic sciences.

The eighth question sought to explore students' views about the most appropriate teaching approach that might not only promote their professionalism but also minimize professional lapses. Students were also asked to evaluate the contribution of the undergraduate formal syllabus of UPMS to their professional development and remediation of unprofessional practices. Finally, in the last question of the questionnaire (item 10), students were asked to write down their commitment towards medical professional development.

Before proceeding with the actual study, the questionnaire was pretested in a sample of 20 undergraduate medical students and was found valid with a Cronbach's $\alpha$ value of 0.75 . This initial pilot study slightly improved the clarity of the core questions and instructions intended to be used in the main survey.

\section{Results}

As mentioned previously, 150 undergraduate students were initially approached in a random fashion, and 134 (89.3\%) of them consented to participate. Fifty-six (41.8\%) of them were males and 78 (58.2\%) females. Seventy-four participants (59\%) were in their fifth year and 60 (41\%) were in their sixth year of study. The demographic characteristics of students according to gender and year of study are presented in Figure 1. Based on students' replies to the 10 main items addressed in the questionnaire, the findings of the survey are presented in detail below.

In response to the first and second item of the questionnaire, it was evident that the majority of students $(n=82$; $61 \%$ ) had personally selected UPMS as their first and foremost choice for studying medicine. The main reason significantly contributing to this was the high prestige attributed to UPMS on national and European grounds; it was also considered to offer an exciting and stimulating learning and research environment, thus providing undergraduate students with higher quality education.

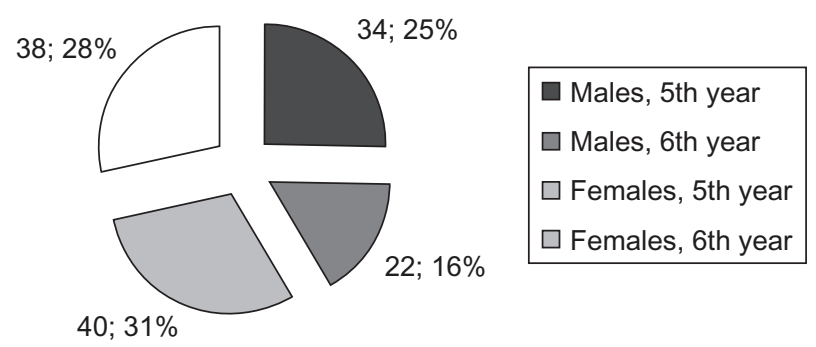

Figure I The demographic characteristics of participants $(n=134)$ by gender and year of study.
In response to the third item of the questionnaire, a large proportion of responders $(n=84 ; 62.7 \%)$ stated that professionalism was significantly associated with their daily clinically-oriented practice in the wards. This perception was significantly prevalent among sixth year students compared to fifth year medical undergraduates (Mann-Whitney U test; $P=0.011)$. In contrast, slightly more than one-third of the overall sample $(n=50 ; 37.3 \%)$ reported that there was a poor association between clinical practice and medical professionalism.

Supportive of the latter finding were the responses in the fourth item of the questionnaire. Students were asked to define the best teaching approach included in their curriculum that promotes professionalism. Daily clinical practice in the wards was regarded by 76 students $(56.7 \%)$ as the most effective setting to develop professionalism, though an integrated curriculum $(n=29 ; 21.6 \%)$ and teaching at the amphitheatre ( $\mathrm{n}=23 ; 17.2 \%)$ were also considered to have a significant impact on this process.

Interestingly, when students were asked to specifically evaluate the significance of an integrated curriculum (item 7), it was disclosed that 105 (78.4\%) of them rated integration as a teaching approach strongly enhances professionalism. Students reported that their main gain from an integrated curriculum was the acquisition of up-to-date medical knowledge derived from the various sectors of medicine.

Responses from the fifth item bolster the view of undergraduate students that their compulsory participation in clinical courses, such as tutorials, seminars, or grand rounds, also reinforces their professionalism. About two-thirds of participants $(n=86 ; 64.1 \%)$ stated that the contribution of clinical activities in developing professionalism is significant. Interestingly, an equal number of students $(n=88 ; 65.7 \%)$ reported that there is a mutual relationship between the clinical and the preclinical components of the syllabus, which facilitates the development of attitudes related to medical professionalism (item 6).

Additionally, it was reported that the most appropriate teaching approach significantly associated with students' professional development and minimization of professional lapses (item 8) was long-term clinically-oriented practice, which has been compulsorily established in the integrated curriculum. Informal discussions with academic staff, in the context of enhanced role modeling, as well as the overall structure of the integrated undergraduate curriculum were highlighted as important issues for high standard learning achievements and professional development. 
Furthermore, $59.7 \%$ of students $(\mathrm{n}=80)$ underlined the importance of the undergraduate formal syllabus of UPMS in significantly contributing to their professional development and consequently to the remediation of unprofessional practices (item 9). In contrast, more than one-third of participants $(n=54 ; 40.3 \%)$ reported that their studies barely enrich their skills so as to reach a sufficient level of professionalism (Table 1). Regarding the independent variables of this research, ie, gender and year of study, neither gender (Chi-square; $P=0.222$ ) nor the year of study (Mann-Whitney U test; $P=0.521$ ) appeared to have significantly influenced the replies of students in this specific question.

Finally, in response to the final question of the questionnaire (item 10) concerning students' commitments towards medical professionalism, a considerable number of students $(\mathrm{n}=60 ; 44.8 \%)$ reported that the acquisition of reliable medical knowledge during their undergraduate studies as well as throughout their career and its wider implications for the benefit of patients are ultimately connected with professional attitudes. Female students were found to give this answer significantly more often than their male colleagues (Chi-Square; $P=0.02$ ), as were fifth year students more than sixth year students (Mann-Whitney $\mathrm{U}$ test; $P=0.000$ ).

A proportion of participants $(n=49 ; 36.6 \%)$ also stated that the rendering of premium quality medical care to patients was included among their main professional commitments. This specific commitment was equally highlighted by both female and male students (Chi-square; $P=0.046$ ). Likewise, year of study was not defined as a predictor of this perception (Mann-Whitney U test; $P=0.94$ ). Only $3.7 \%$ of students $(\mathrm{n}=5)$ rated the provision of basic and absolutely necessary health care to patients in relation to the health problem they face as being amongst their main commitments to patients. The answers of students on this specific item by gender and year of study are summarized in Table 2 .

\section{Discussion}

The reputation of medicine has been questioned in recent years as the perception of caring for those who cannot afford medical care has not maintained its validity. The main reason accounting for this is the view that physicians put their own interest above that of the public, disregarding at the same time the meaning of altruism and ethical conduct. ${ }^{23}$

Nevertheless, patients expect physicians to be competent, moral, and altruistic, thus being professionals in the broader sense of the term. Indeed, the results of a study, in which 192 randomly selected patients were asked to report the ideal physician behavior, support the latter view. In that setting, telephone interviews were conducted and focused on the physician-patient relationship. The ideal physician was described as someone having a professional attitude reflecting upon six principal characteristics, namely being confident, empathetic, humane, personal, forthright, and respectful. ${ }^{24}$ Considering patients' and societal expectations, Arnold and Stern have proposed a framework to define professionalism, to promote its teaching, and develop tools for assessing it. ${ }^{25}$ This framework requires physicians to be clinically competent, humanistic, and moral; communication skills are also necessary to satisfy the expectations of patients and society.

In this regard it is worth mentioning that professionalism is included among the six competencies proposed for undergraduate students by the Accreditation Council for Graduate Medical Education (ACGME). According to ACGME, the definition of professionalism is multidimensional and requires students to obtain fundamental professionalism-related attitudes before graduating, such as respect, compassion, integrity, responsiveness, altruism, accountability, commitment to excellence, sound ethics, and sensitivity to diversity. ${ }^{26}$

Current knowledge shows that there are several reasons for developing professionalism in undergraduate medical students. The main rationale of such a process suggests that professionalism can be both learned and assessed

Table I Students' views about the contribution of University of Patras Medical School's formal syllabus to their professional development

\begin{tabular}{|c|c|c|c|c|c|c|}
\hline & $\begin{array}{l}\text { Males, 5th year } \\
(\mathrm{N} ; \%)\end{array}$ & $\begin{array}{l}\text { Males, 6th year } \\
(\mathrm{N} ; \%)\end{array}$ & $\begin{array}{l}\text { Females, 5th year } \\
(\mathrm{N} ; \%)\end{array}$ & $\begin{array}{l}\text { Females, 6th year } \\
(\mathrm{N} ; \%)\end{array}$ & $\begin{array}{l}\text { Total } \\
(\mathbf{N})\end{array}$ & $\begin{array}{l}\text { Sum } \\
(\mathbf{N} ; \%)\end{array}$ \\
\hline Very much & I; $2.9 \%$ & - & $2 ; 5 \%$ & I; $2.6 \%$ & 4 & \\
\hline Much & $3 ; 8.8 \%$ & $3 ; 13.6 \%$ & $7 ; 17.5 \%$ & $8 ; 21.1 \%$ & 21 & \\
\hline Well enough & $16 ; 47.1 \%$ & $7 ; 31.8 \%$ & $17 ; 42.5 \%$ & $15 ; 39.5 \%$ & 55 & $80 ; 59.7 \%$ \\
\hline Slightly & $8 ; 23.5 \%$ & II; 50\% & II; $27.5 \%$ & I4; 36.8\% & 44 & $54 ; 40.3 \%$ \\
\hline \multirow[t]{2}{*}{ Not at all } & $6 ; 17.6 \%$ & I; $4.5 \%$ & $3 ; 7.5 \%$ & - & 10 & \\
\hline & $N=34$ & $N=22$ & $N=40$ & $N=38$ & & \\
\hline Total (N) & 56 & & 78 & & 134 & \\
\hline
\end{tabular}


Table 2 Students' views about their main commitments for provision of health care to patients

\begin{tabular}{llllll}
\hline & Males, 5th year (N; \%) & Males, 6th year (N; \%) & Females, 5th year (N; \%) & Females, 6th year (N; \%) & Total (N; \%) \\
\hline Quality care & I2; 35.3\% & $10 ; 45.6 \%$ & $10 ; 25 \%$ & $17 ; 44.7 \%$ & $49 ; 36.6 \%$ \\
Being frank & $6 ; 17.5 \%$ & $1 ; 4.5 \%$ & $4 ; 10 \%$ & $4 ; 10.5 \%$ & $15 ; 11.2 \%$ \\
Prevention & $2 ; 5.9 \%$ & $1 ; 4.5 \%$ & $1 ; 2.5 \%$ & $1 ; 2.6 \%$ & $5 ; 3.7 \%$ \\
Basic care & - & $3 ; 13.6 \%$ & - & $2 ; 5.3 \%$ & $5 ; 3.7 \%$ \\
Reliable care & $\mid 4 ; 41.2 \%$ & $7 ; 31.8 \%$ & $25 ; 62.5 \%$ & $14 ; 36.8 \%$ & $60 ; 44.8 \%$ \\
Total (N) & 56 & & 78 & & $134 ; 100 \%$ \\
\hline
\end{tabular}

and this cannot be done merely by chance. Additionally, professionalism is associated with improved medical outcomes and less adverse medical outcomes. ${ }^{27}$

The survey results presented herein reflect the attitudes of a likely representative sample of Greek undergraduate medical students relating to medical professionalism. To the best of the authors' knowledge, this is the first time in Greece in which students' views about medical professionalism have been deliberately solicited. Taking into consideration the multidimensional aspect of medical professionalism, ${ }^{7,26}$ the questionnaire used in this survey was designed to identify the core elements of undergraduate students' perceptions regarding medical professionalism and to reveal their attitudes related to this issue. Fifth and sixth year undergraduate students, having already accomplished the preclinical component of their studies and almost finished their clinical practice (fifth and sixth year of study), were considered to have adequately developed the appropriate skills and attitudes for the formation of their medical professional profile. For this reason, students were not asked to describe the concept of professionalism but, instead, they were called to identify the overall impact of the UPMS curriculum on the process of their professional formation and development. In this research framework, the authors sought to explore students' views about the potentially effective ways for the enhancement of professionalism and the minimization of professional lapses.

Nevertheless, these results cannot be generalized mainly because of the cross-sectional design of the research and the limited setting of the case study. Another issue, which might bias the answers given by this sample, is associated with the lack of a common concept of professionalism in general and medical professionalism in particular. In support of this view, there is evidence that a considerable number of undergraduate students are unaware of the fundamental values of professionalism. ${ }^{28}$ Despite these restrictions, selection bias was avoided, because the survey was based on a random sample of medical students.

In this context, some of the results deserve to be highlighted. The first issue that needs to be emphasized is the great significance given by students to daily clinically-oriented activities during the last 2 years of their undergraduate medical studies in the constellation of behaviors consistent with medical professionalism. According to results, it was clearly evident that daily clinical practice in the wards was regarded by students as the most effective way to realize the core elements of their professionalism. The structure of an integrated curriculum and informal discussions with members of academic staff, who were acting as models/prototypes in the formation of their medical profession, were also recognized as significantly contributing to the accomplishment of this issue. Finally, students in this sample reported that their main commitment to provide a professionally proper medical service was associated with the acquisition of appropriate and reliable medical knowledge and skills for the benefit of patients.

Comparing these results with those revealed in other similar studies underlines the common belief that clinicallyoriented teaching activities together with an integrated undergraduate curriculum are highly valued for the development of professional medical attitudes. ${ }^{29,30}$ Informal discussions with role models also play an important role in the professional socialization of undergraduate medical students, ${ }^{31}$ and this effect was evident in this setting. Additionally, previous studies conducted on this topic highlight the importance of enhancing role modeling in promoting professional behaviors to trainees of diverse origins. ${ }^{17,32}$ Physicians defined as excellent role models should fulfill two conditions: to spend time educating their students and to cultivate the significance of a comprehensive approach to patients' care. ${ }^{33}$

Students were also asked to envision their work in medicine as an expression of their highest values and commitment to patients. Their personal statements contained attributes regarding premium professional skills where they advocated constancy and perfectionism throughout a lifelong learning process so as to be able to provide high quality medical care to patients. These ideas reveal students' aspirations and provide insights into the way a national cadre of medical undergraduate students view professionalism. In line with 
these results, commitment to learning and improvement of undergraduate studies to serve the primacy of patient welfare in the practice of medicine and research are additionally included in the informal (hidden) curriculum of students attending the Mayo Clinic. ${ }^{34}$

In summary, undergraduate students in this sample perceive the final 2 years of their studies as quite important in understanding the essence of professionalism and thoroughly building their professional medical attitudes. Taking a deeper look into the undergraduate syllabus of UPMS has highlighted students' perceptions of professionalism outside the formal curriculum. Additionally, taking into account the fact that about $40 \%$ of students in this sample stated that there was no association with the content of the formal syllabus and promotion of professional attitudes, this finding might be related to the emphasis students placed on acquiring knowledge to provide reliable medical care and the importance they attributed to more learning activities such as amphitheatre teaching, seminars, and ground rounds for their professional development. As such, UPMS might be offered a challenge to reflect upon these data and reconsider the curriculum in its content and in its context. Moreover, this case study could contribute to the initiation of relevant research projects at a national and cross-national level. Overall, it seems that the increase of awareness regarding professionalism in undergraduate medical students deserves the attention of medical schools' authorities not only in Greece but in other countries as well. Developing professionalism-consistent attitudes should be regarded as a continuing process of strengthening the core elements of physicians' background and ultimately reinforcing their medical professional identity throughout their career.

\section{Acknowledgment}

Each author contributed equally in the preparation of this article. All authors have seen and approved the final version. We would like to express our thanks to Ms Emilia Lymberopoulou for her contribution to the collection of data.

\section{Disclosure}

The authors report no conflicts of interest in this work.

\section{References}

1. Aristotle. Ethica Nicomacheia. 350BC:1140A1-1141A24.

2. Freire P. Pedagogy of the oppressed. New York: Continuum; 1986.

3. Wear D. The medical humanities: toward a renewed praxis. $J$ Med Humanit. 2009;30(4):209-220.

4. Frei E, Stamm M, Buddeberg-Fischer B. Mentoring programs for medical students-a review of the PubMed literature 2000-2008. BMC Med Educ. 2010;10:32.
5. Abbot P, Meerabeau L. Professionals, professionalization and the caring professions. In: Abbot P, Meerabeau L, editors. The sociology of the caring professions. Abingdon, Oxfordshire: Routledge; 1998:1-19.

6. Working Party of the Royal College of Physicians. Doctors in society. Medical professionalism in a changing world. Clin Med. 2005;5 (6 Suppl 1):S5-S40.

7. van Mook WN, van Luijk SJ, O'Sullivan H, et al. The concepts of professionalism and professional behaviour: conflicts in both definition and learning outcomes. Eur J Intern Med. 2009;20(4):e85-e89.

8. Tallis RC. Doctors in society: medical professionalism in a changing world. Clin Med. 2006;6(1):7-12.

9. Plochg T, Klazinga NS, Starfield B. Transforming medical professionalism to fit changing health needs. BMC Med. 2009;7:64.

10. Stephenson A, Higgs R, Sugarman J. Teaching professional development in medical schools. Lancet. 2001;357(9259):867-870.

11. Papadakis MA, Loeser H, Healy K. Early detection and evaluation of professionalism deficiencies in medical students: one school's approach. Acad Med. 2001;76(11):1100-1106.

12. Hatem CJ. Teaching approaches that reflect and promote professionalism. Acad Med. 2003;78(7):709-713.

13. Cohen JJ. Professionalism in medical education, an American perspective: from evidence to accountability. Med Educ. 2006;40(7):607-617.

14. Swick HM, Szenas P, DanoffD, Whitcomb ME. Teaching professionalism in undergraduate medical education. JAMA. 1999;282(9):830-832.

15. Steinert Y, Cruess S, Cruess R, Snell L. Faculty development for teaching and evaluating professionalism: from programme design to curriculum change. Med Educ. 2005;39(2):127-136.

16. Steinert Y, Cruess RL, Cruess SR, Boudreau JD, Fuks A. Faculty development as an instrument of change: a case study on teaching professionalism. Acad Med. 2007;82(11):1057-1064.

17. Baingana RK, Nakasujja N, Galukande M, Omona K, Mafigiri DK, Sewankambo NK. Learning health professionalism at Makerere University: an exploratory study amongst undergraduate students. $B M C$ Med Educ. 2010;10:76.

18. Arnold L. Assessing professional behavior: yesterday, today, and tomorrow. Acad Med. 2002;77(6):502-515.

19. Greek State. Law No. 641, Issue A, provided for the foundation and organization of Medical Schools at the Universities of Patras, Ioannina and Thrace. July 22, 1977. Available from: http://www.et.gr/index. php?option=com_wrapper\&view=wrapper\&Itemid=108\&lang=en. Accessed November 20, 2010.

20. Greek State. Presidential Decree 127, Issue A, provided for the structure of schools at the University of Patras. March 3, 1983. Available from: http://www.et.gr/index.php?option=com_wrapper\&view=wrapper\&It emid=108\&lang=en. Accessed November 20, 2010.

21. Cokkinos DV, Katsilambros NL, Toumanidis S. Medical education in Greece: the role of HASME. Clin Teacher. 2006;3(4):254-255.

22. Wear D. On white coats and professional development: the formal and the hidden curricula. Ann Intern Med. 1998;129(9):734-737.

23. Stevens RA. Public roles for the medical profession in the United States: beyond theories of decline and fall. Milbank Q. 2001;79(3): 327-353.

24. Bendapudi NM, Berry LL, Frey KA, Parish JT, Rayburn WL. Patients' perspectives on ideal physician behaviors. Mayo Clin Proc. 2006;81(3):338-344.

25. Arnold L, Stern DT. What is medical professionalism? In: Stern DT, editor. Measuring medical professionalism. New York NY: Oxford University Press; 2006:15-38.

26. ACGME Outcome Project. Advancing education in medical professionalism. 2004. Available from: http://www.acgme.org/outcome/ implement/Profm_resource.pdf. Accessed December 1, 2010.

27. Stern DT, Papadakis M. The developing physician - becoming a professional. N Engl J Med. 2006;355(17):1794-1799.

28. Hafferty FW. What medical students know about professionalism. Mt Sinai J Med. 2002;69(6):385-397. 
29. Barry D, Cyran E, Anderson RJ. Common issues in medical professionalism: room to grow. Am J Med. 2000;108(2):136-142.

30. Roberts LW, Green Hammond KA, Geppert CM, Warner TD. The positive role of professionalism and ethics training in medical education: a comparison of medical student and resident perspectives. Acad Psychiatry. 2004;28(3):170-182.

31. Donetto S. Medical students' views of power in doctor-patient interactions: the value of teacher-learner relationships. Med Educ. 2010;44(2):187-196.
32. Loh KY, Nalliah S. Learning professionalism by role-modelling. Med Educ. 2010;44(11):1123.

33. Wright SM, Kern DE, Kolodner K, Howard DM, Brancati FL. Attributes of excellent attending-physician role models. N Engl J Med. 1998;339(27):1986-1993.

34. Viggiano TR, Pawlina W, Lindor KD, Olsen KD, Cortese DA. Putting the needs of the patient first: Mayo Clinic's core value, institutional culture, and professionalism covenant. Acad Med. 2007;82(11):1089-1093.

\section{Publish your work in this journal}

Advances in Medical Education and Practice is an international, peerreviewed, open access journal that aims to present and publish research on Medical Education covering medical, dental, nursing and allied healthcare professional education. The journal covers undergraduate education, postgraduate training and continuing medical education including emerging trends and innovative models linking education, research, and healthcare services. The manuscript management system is completely online and includes a very quick and fair peer-review system. Visit http://www.dovepress.com/testimonials.php to read rea quotes from published authors.

Submit your manuscript here: http://www.dovepress.com/advances-in-medical-education-and-practice-journal 